\title{
ESTUDO COMPARATIVO DO DESEMPENHO TÉRMICO DAS COBERTURAS DE FIBRA DE CELULOSE E BETUME, FIBROCIMENTO E CERÂMICA
}

\section{COMPARATIVE STUDY OF THERMAL PERFORMANCE OF COVERAGE OF FIBER PULP AND FILLER, FIBER CEMENT AND CERAMIC}

José Augusto Alves Pimenta ${ }^{1}$, João Miguel Merces Bega ${ }^{2}$, Marcel Tsubasa Saito ${ }^{1}$, Leila Maria Sotocorno e Silva ${ }^{1}$, Filipe Bittencourt Figueiredo ${ }^{1}$, Maria Alessandra Bacaro Boscoli ${ }^{1}$, Renivaldo José dos Santos $^{3}$

Universidade do Oeste Paulista - UNOESTE, Faculdade de Engenharia de Presidente Prudente-FEPP ${ }^{1}$, Universidade Estadual Paulista - UNESP, Faculdade de Engenharia de Ilha Solteira - FEIS ${ }^{2}$, Universidade Estadual Paulista - UNESP, Campus Experimental de Rosana ${ }^{3}$

E-mail: josepimenta37@gmail.com

RESUMO - Os materiais utilizados como cobertura têm grande influência no aumento da temperatura do ambiente urbano, afetando diretamente o conforto térmico de seus usuários. Sendo assim, a presente pesquisa teve como objetivo desenvolver um estudo comparativo do desempenho térmico de três tipos de cobertura, sendo elas: fibra de celulose e betume, fibrocimento e cerâmica. Para tal, foi realizada a construção de um protótipo que representa em escala menor uma residência, e com o uso de dois equipamentos confortímetro Sensu, foram realizadas medições de temperatura do ar, temperatura radiante média e umidade relativa do ar dentro e fora do protótipo. Com base nos resultados obtidos, verificou-se que a cobertura de cerâmica apresentou o melhor desempenho térmico.

Palavras-chave: Cobertura; Desempenho Térmico; Confortímetro.

ABSTRACT - The materials used as cover have great influence on the increase of the urban environment temperature, directly affecting the thermal comfort of its users. Thus, the present study aimed to develop a comparative study of the thermal performance of three types of coverage, which are: cellulose fiber and bitumen, cement and ceramics. To this end, the construction of a prototype that represents on a smaller scale a residence has been carried out and with the use of two confortímetro Sensu equipment, they were carried out air temperature measurements, mean radiant temperature and relative

Recebido em: $19 / 08 / 2016$ Revisado em: 22/08/2016 Aprovado em: 02/09/2016 humidity within and outside of the prototype. Based on these results, it was found that the ceramic cover made, the best thermal performance.

Keywords: Coverage; Thermal Performance; Confortímetro. 


\section{INTRODUÇÃO}

O cenário atual em que a sociedade continua a se desenvolver, utilizando como fonte de matéria prima e energia os recursos naturais, vêm causando sérios danos ambientais. Nesse contexto, a redução dos impactos negativos causados pela construção civil é um fator de suma importância na busca de um desenvolvimento sustentável.

O projeto de construções mais eficientes é um dos desafios que os engenheiros e arquitetos enfrentam. Como complementa Teixeira (1977), "Não é mais possível pensar em projetar edificações com novos padrões estéticos, novas tecnologias, em novos contextos (de organização espacial, de organização social, de inserção de novas mídias) com os antigos padrões de consumo energético."

Algumas iniciativas empreendidas por governos e empresas, realizaram pesquisas a fim de quantificar os problemas que geram essas preocupações. O World Business Council for Susteinable Development (WBCSD) realizado em 2011 avaliou vários países dentre eles "Brasil, China, Índia, países da União Europeia, Japão e Estados Unidos que em conjunto constituem mais da metade da população mundial [...] e são responsáveis por dois terços da demanda de energia no âmbito mundial" (JARDIM, 2011).
Os resultados mostraram que cerca de $40 \%$ da energia utilizada são destinadas as edificações. Além disso, foi verificado que dessa porcentagem, $84 \%$ do consumo energético ocorre na adequação do conforto térmico da edificação durante a utilização do edifício, "e que a envoltória do mesmo passa a ser, então, o ponto de partida da eficiência e a principal determinante da quantidade de energia que será necessária para aquecer e ventilar o edifício" (JARDIM, 2011).

Os materiais empregados na construção da envoltória têm grande influência na temperatura interna das edificações, já que ela separa os ambientes interno e externo. Dentre as partes da envoltória, as coberturas representam uma parcela significativa da transferência de calor entre os ambientes, segundo Gartland (2010) "as coberturas cobrem cerca de $20 \%$ das áreas urbanas e suburbanas e são as características mais quentes vistas às imagens termais em cidades. "

Devido à falta de conhecimento técnico sobre propriedades e características dos materiais, os profissionais tendem a se preocupar somente com o preço. Daí surge a necessidade de maior atenção quanto à escolha de tais materiais, uma vez que os mesmos: "[...] servem de subsídios para elaboração de projetos visando à economia de energia ou, em grande parte do território nacional, para encontrar soluções 
construtivas que propiciem condições satisfatórias de conforto térmico aos usuários sem utilizar equipamentos de condicionamento ambiental. " (VITTORINO; SATO; AKUTSU, 2003).

Para realização do trabalho foram utilizados três tipos de cobertura, a escolha destas se justifica em: Telha de fibrocimento e cerâmica por serem já bastante difundidas no mercado; já a telha de fibra de celulose e betume por ser um produto relativamente novo no mercado brasileiro oriundo da reciclagem de fibras de celulose da indústria com produção ecologicamente correta.

Em regiões que sofrem com as altas temperaturas ao decorrer do ano, como é o caso de Presidente Prudente, é imprescindível considerar o tipo de cobertura a se utilizar. Sabe-se que as coberturas estão o dia todo em contato direto com a radiação solar, portanto, a escolha do material é um fator que determinará as condições térmicas no interior da edificação.

Logo, a investigação e comparação das características térmicas dos três tipos de coberturas, poderão servir de subsídios para a escolha de material, visando garantir condições satisfatórias de conforto térmico aos usuários.

Sendo assim, o objetivo na presente pesquisa foi comparar o desempenho térmico de três tipos de cobertura, sendo elas: fibra de celulose e betume, fibrocimento e cerâmica.

\section{METODOLOGIA}

\subsection{CARACTERIZAÇÃO CLIMÁTICA DE PRESIDENTE PRUDENTE}

As medições foram realizadas na Universidade do Oeste Paulista, situada na zona oeste da cidade de Presidente Prudente, que por sua vez está localizada no oeste do estado de São Paulo $22^{\circ} 07^{\prime} 04^{\prime \prime}$ de latitude Sul e $51^{\circ} 22^{\prime} 57^{\prime \prime}$ de longitude Oeste. A 475 metros acima do nível do mar. A Figura 1 apresenta o zoneamento bioclimático brasileiro (NBR 1520-3), em que Presidente Prudente se encontra na zona 6.

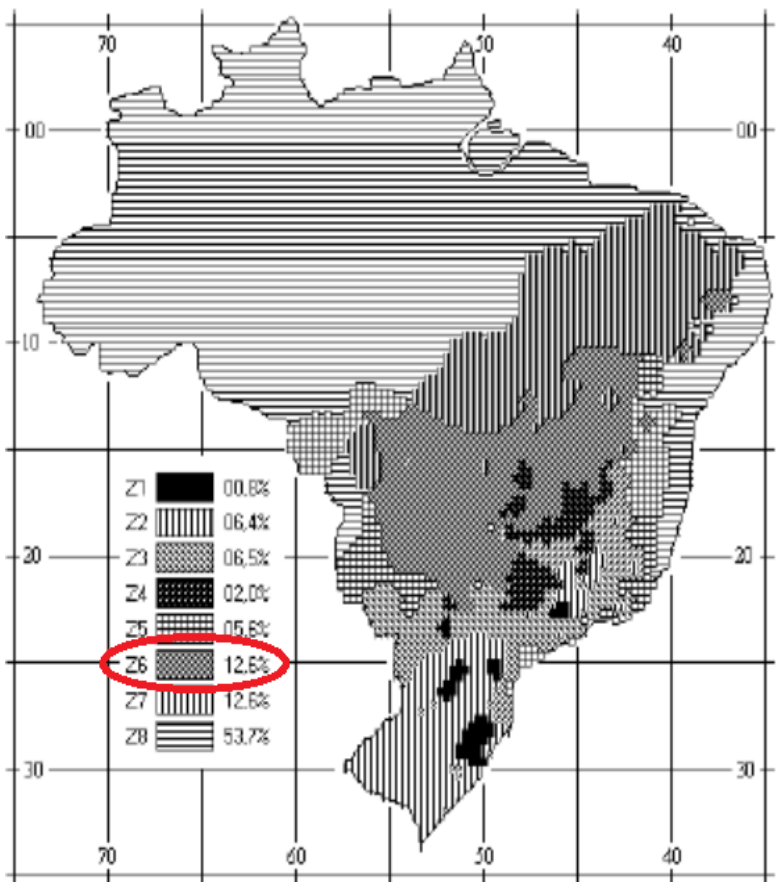

Figura 1. Mapa de zoneamento climático brasileiro.

Fonte: (ABNT, 2005).

"Trata-se de uma cidade tipicamente tropical que possui um período quente e chuvoso entre outubro e março e, outro mais 
ameno e seco, entre abril e setembro". (AMORIM, 2012). Sant'Anna Neto e Tommaselli (2012) complementam que, “[...] a cidade de Presidente Prudente situa-se numa área de transição entre os climas zonais controlados pelos sistemas tropicais, que the conferem elevadas temperaturas de primavera e verão, e pelos sistemas extratropicais (massas polares) que ocasionam episódios de invasão das frentes frias e do ar polar no outono e inverno, provocando baixas temperaturas. "

A malha urbana de Presidente Prudente se expandiu muito nos últimos anos, hoje a cidade com cerca de 210 mil habitantes (IBGE, 2010), sofre com alguns dos problemas encontrados nos grandes centros, como enchentes e ilha de calor.

\subsection{MATERIAIS DE COBERTURA UTILIZADOS}

Para a realização do trabalho foram analisados três tipos de coberturas, seguem na Tabela 1 as características dos materiais.
Tabela 1. Características dos materiais utilizados.

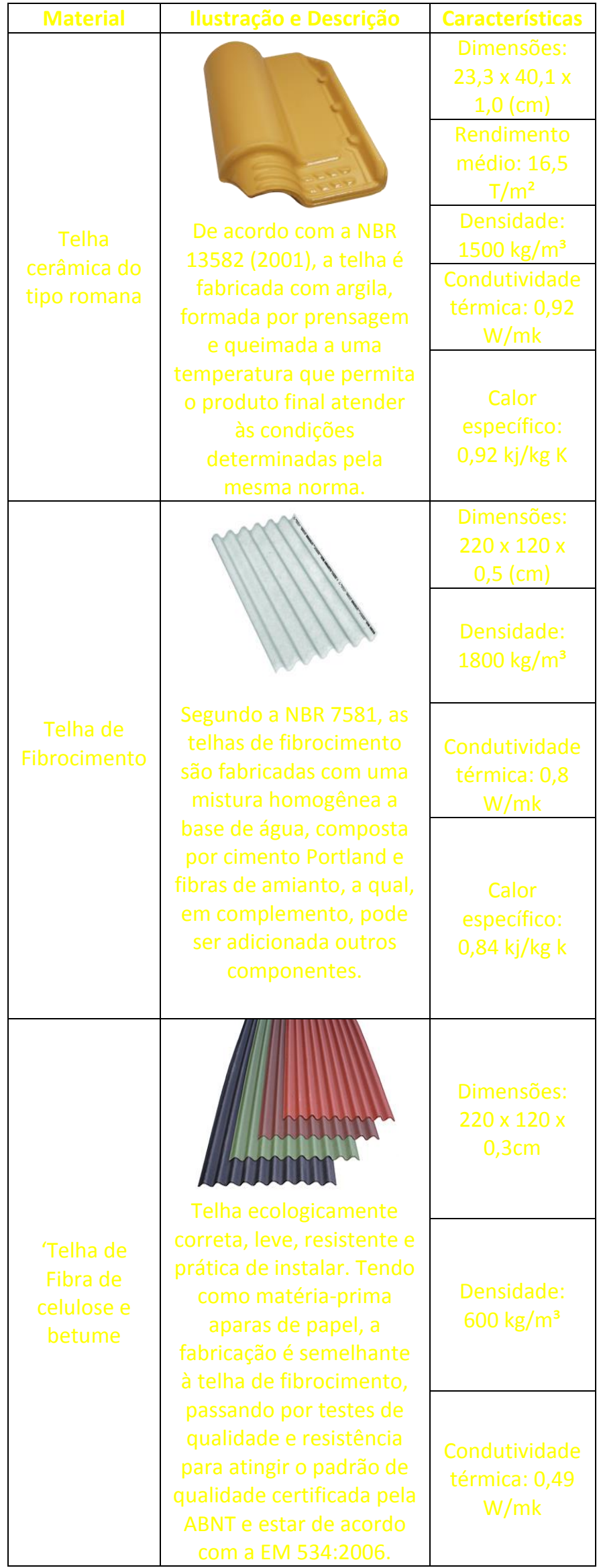

Fonte: (Autores, 2016). 


\subsection{PROCEDIMENTO DE CONSTRUÇÃO DO PROTÓTIPO}

Para realização do trabalho foi realizada a construção de um protótipo, que representa em menor escala, uma edificação simples de dimensões $2,1 \mathrm{~m} \times 1,05 \mathrm{~m} \times 0,6 \mathrm{~m}$.

Para confeç̧ão do protótipo foram necessárias oito placas de madeirite de dimensões 2,1 x 1,2 (m). 0 projeto de construção foi idealizado de modo que as paredes fossem como câmaras de ar sem circulação. Essas câmaras foram projetadas de maneira que isolassem termicamente as paredes, permitindo assim que o calor que entre dentro da maquete seja em sua maior parte proveniente da cobertura.

As placas foram fixadas em placas de madeira, proveniente de restos de construções da UNOESTE com auxílio de parafusos, como demonstra a Figura 2.
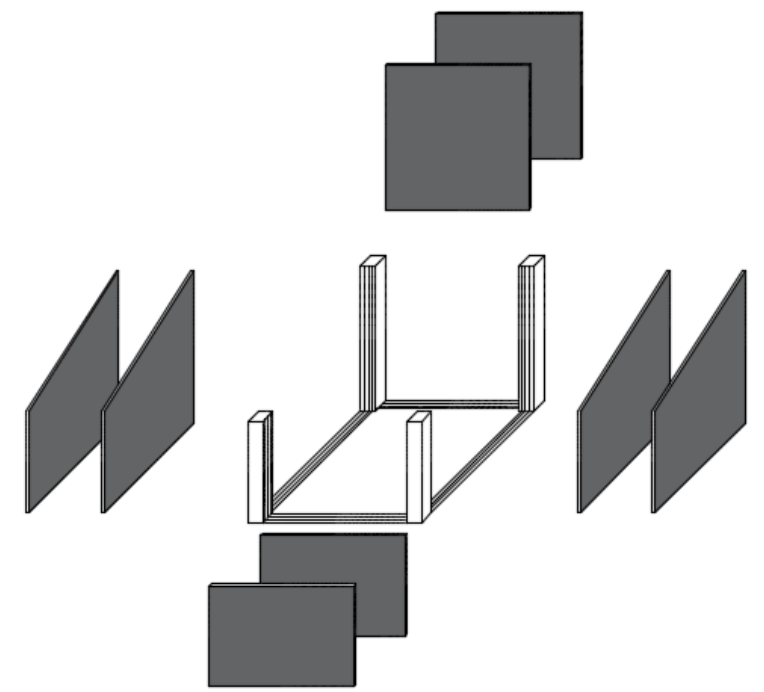

Figura 2. Vista 3D do protótipo. Fonte: (Autores, 2016).

As dimensões do protótipo foram executadas na proporção 2:1, que representa a maioria das formas das edificações brasileiras.

No topo de cada parede foi implantada uma "tampa" removível, que isola a câmara de ar da parede e permite abertura para eventuais utilizações de enchimentos. O protótipo é demonstrado na Figura 3.

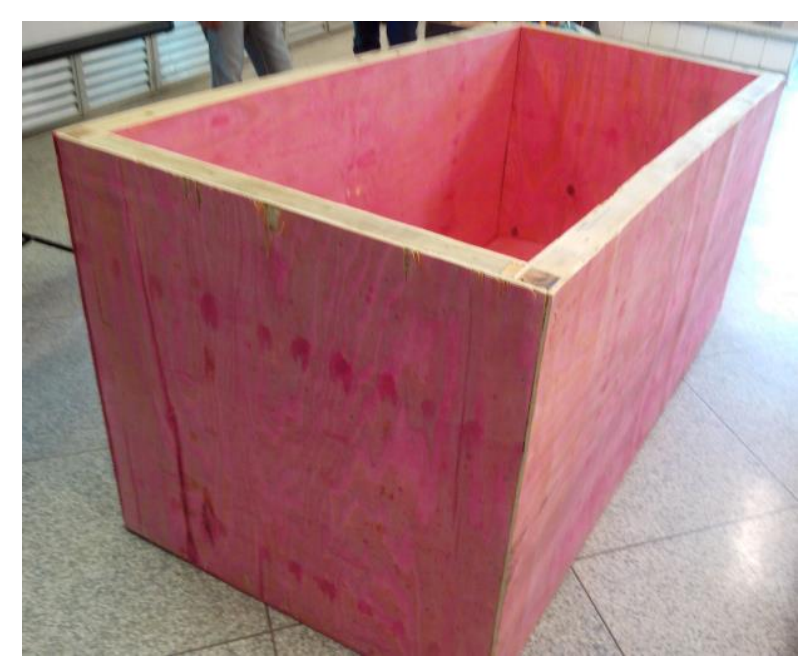

Figura 3. Protótipo $2: 1$ montado com placas de madeirite. Fonte: (Autores, 2016).

Para a instalação das telhas de cerâmica foi confeccionada uma estrutura de madeira de suporte. Como segue na Figura 4. 


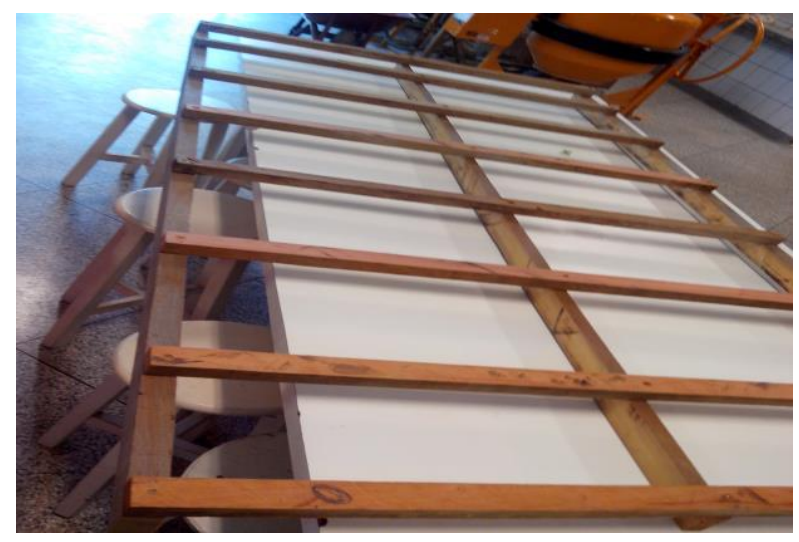

Figura 4. Estrutura de suporte da cobertura.

Fonte: (Autores, 2016).

\subsection{METODOLOGIA DE AQUISIÇÃO DOS DADOS}

Como se pretendia-se obter as condições mais próximas da realidade possível, as medições foram realizadas simultaneamente, para garantir que os dados externo e interno pudessem ser comparados em um mesmo instante. Ou seja, um dos equipamentos foi instalado dentro do protótipo, enquanto outro foi alocado do lado de fora, próximo a maquete. O protótipo foi instalado dentro do campus II da UNOESTE como mostra a Figura 5.

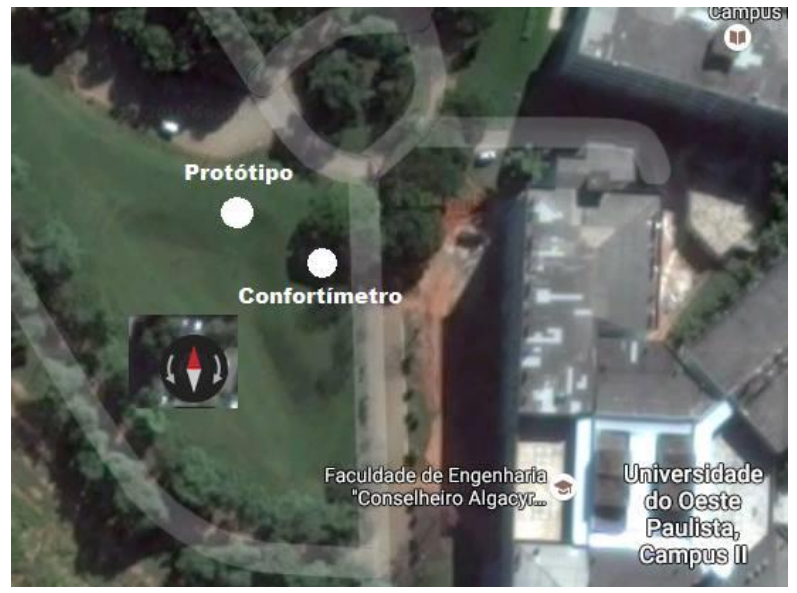

Figura 5. Localização dos confortímetros. Fonte: (Adaptado de Google Maps, 2016).
Para realização das medições foi utilizado o confortímetro Sensu (Figura 6), equipamento confeccionado no Laboratório de Meios Porosos e Propriedades Termo físicas (LMTP) da Universidade Federal de Santa Catarina (UFSC).

O confortímetro Sensu consiste num equipamento portátil de aquisição de sinais, baseado em uma plataforma PC compactada. Sua interface gráfica e touch screen, possui o sistema operacional Windows, e o monitoramento das medições é realizados por meio do software SENSU (Figura 7), que salva os dados coletados pelos sensores em arquivo no formato txt (bloco de notas). As variáveis medidas pelo equipamento neste estudo são:

- Temperatura do Ar;

- Temperatura Radiante Média;

- Umidade Relativa do Ar.

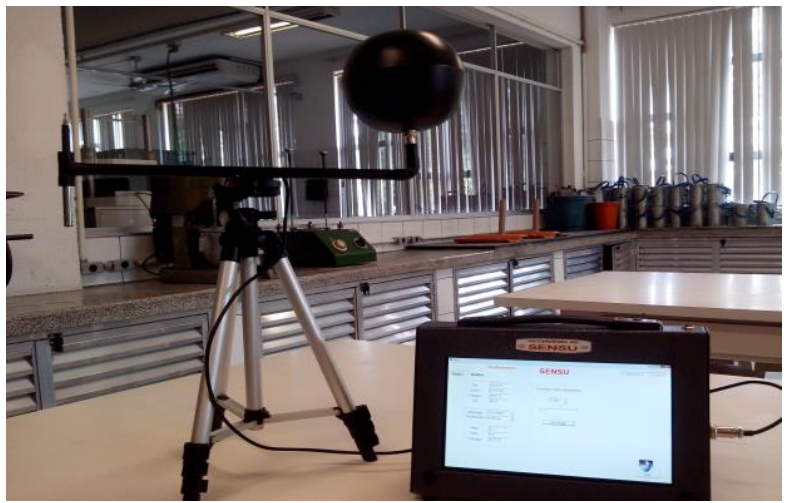

Figura 6. Confortímetro Sensu.

Fonte: (Autores, 2016). 


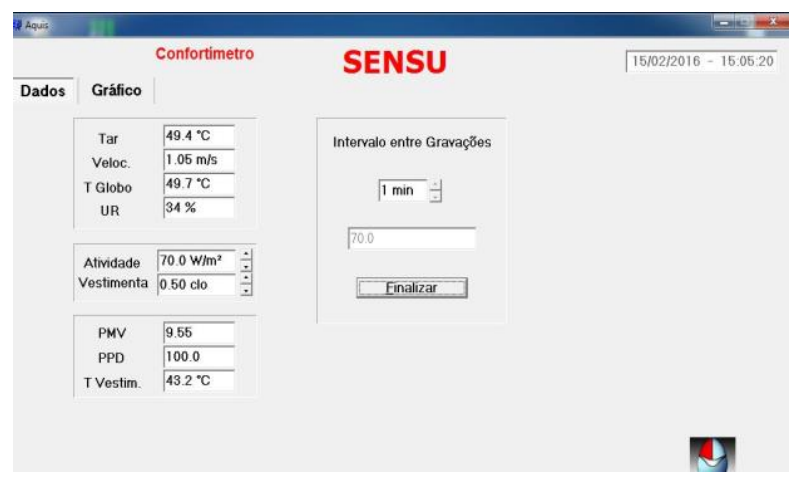

Figura 7. Interface do Software Sensu.

Fonte: (Autores, 2016).

O software que monitora as medições realizadas pelo equipamento também gera, em tempo real, um gráfico com as variáveis medidas, de modo a deixar mais claro a interpretação dos dados no local, como apresentado na Figura 8.

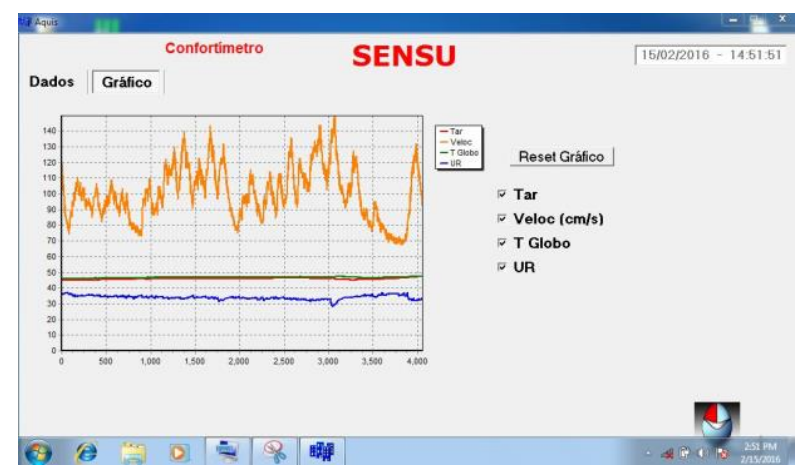

Figura 8. Interface com gráfico em tempo real.

Fonte: (Autores, 2016).

As medições foram realizadas num intervalo de 10 minutos com cada cobertura, de modo que o período escolhido para as medições permitisse a realização das mesmas com todas as coberturas, sem que houvesse uma grande mudança de características climáticas entre elas.

Um dos confortímetros foi alocado dentro do protótipo centralizado, como mostra a Figura 9. Logo após isso, foi colocada a cobertura e foi esperado um período de 10 minutos para dar-se início as medições. Isso foi feito para que houvesse uma estabilização da temperatura do ar no interior do protótipo, e para que a cobertura já estivesse devidamente ambientada com a temperatura local.

Para a alimentação das baterias do equipamento foram instalados pontos de tomada logo ao lado do local onde seriam realizadas as medições.

Do lado de fora foi instalado o segundo confortímetro (Figura 10) sob a sombra de uma árvore de modo a impedir que a radiação solar direta interferisse nas medições da temperatura do ambiente externo.

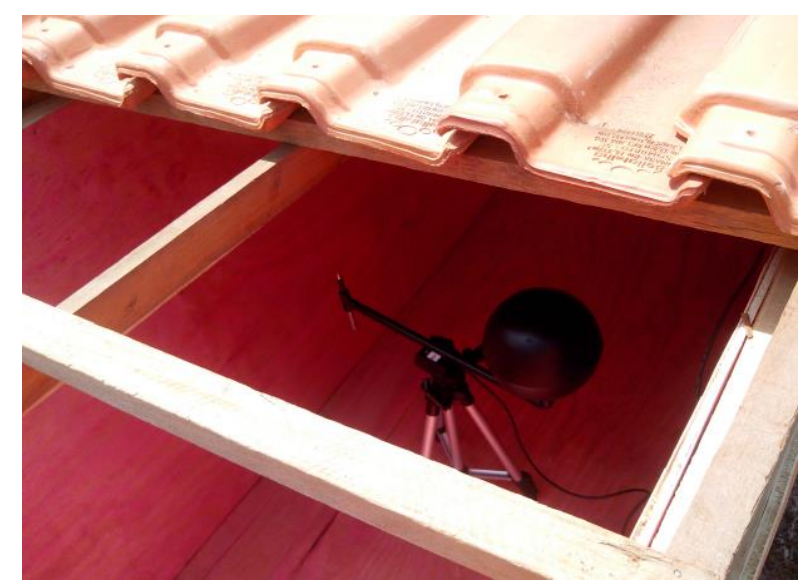

Figura 9. Confortímetro dentro do protótipo.

Fonte: (Autores, 2016). 


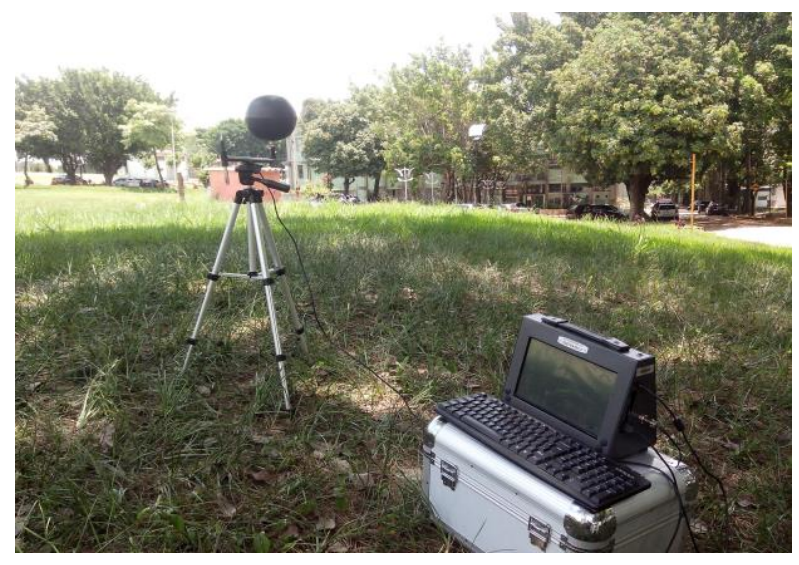

Figura 10. Confortímetro externo. Fonte: (Autores, 2016).

Os dias de aquisição dos dados foram os de 14, 17, 21 e 22 de março de 2016, escolhido devido a ser próximo ao equinócio de Outono, época em que a latitude de estudo, o sol se encontra a pino, ou seja, sua trajetória do amanhecer até o anoitecer se dá no centro da abóboda celeste.

Nessa época o ganho térmico nos horários das 10 da manhã até as 14 horas são quase que totalmente proveniente de planos verticais, ou seja, da cobertura.

Como o protótipo desenvolvido possui uma água, ele foi alinhado de modo que os raios solares incidissem diretamente na inclinação de cobertura existente. Para tanto, com auxílio de uma bússola, ele foi alinhado na posição perpendicular (90)) ao norte.

\section{RESULTADOS}

\subsection{RESULTADOS DA MEDIÇÃO TESTE}

No dia 14 de março de 2016, foi realizada uma medição teste, para averiguar se a metodologia desenvolvida funcionaria.
Foi verificado nesse dia que um dos sensores de velocidade do vento de um dos confortímetros não estava funcionando adequadamente, portanto, essa variável foi eliminada do estudo. O clima local apresentava as seguintes características, segundo dados obtidos na página do INPE:

- Direção do Vento: SE - 20km/h;

- Umidade Relativa: entre 46 e 82\%;

- Temperatura mínima: 20ㄷ;

- Temperatura máxima: 33ㄷ․

O céu possuía bastante nebulosidade, com uma velocidade do vento moderada.

\subsubsection{TELHA DE FIBROCIMENTO}

A primeira medição realizada foi com a cobertura de fibrocimento e teve início às $14 \mathrm{~h}$ e $29 \mathrm{~min}$ e término às $14 \mathrm{~h}$ e $39 \mathrm{~min}$.

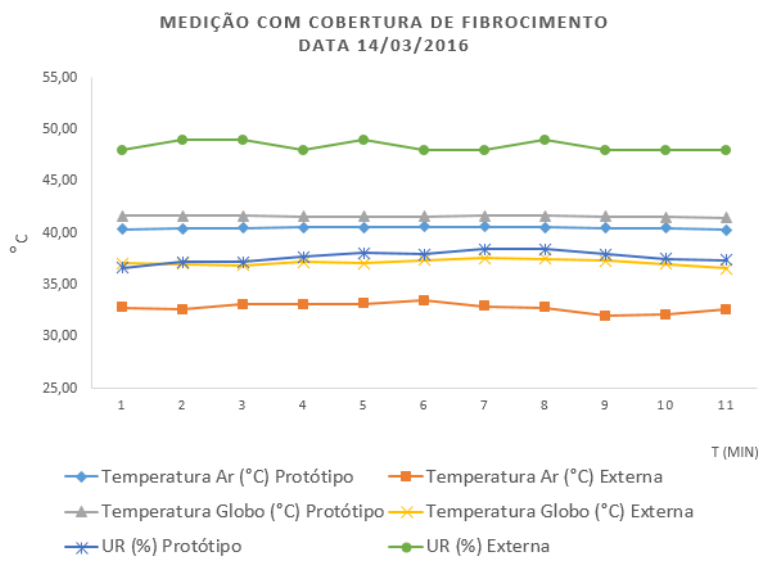

Figura 11. Gráfico da medição com cobertura de fibrocimento dia 14/03/2016. Fonte: (Autores, 2016). 


\subsubsection{TELHA DE FIBRA DE CELULOSE E BETUME}

A segunda medição foi realizada com a telha de fibra de celulose e betume, no período das $15 \mathrm{~h}$ até às $15 \mathrm{~h}$ e $10 \mathrm{~min}$.

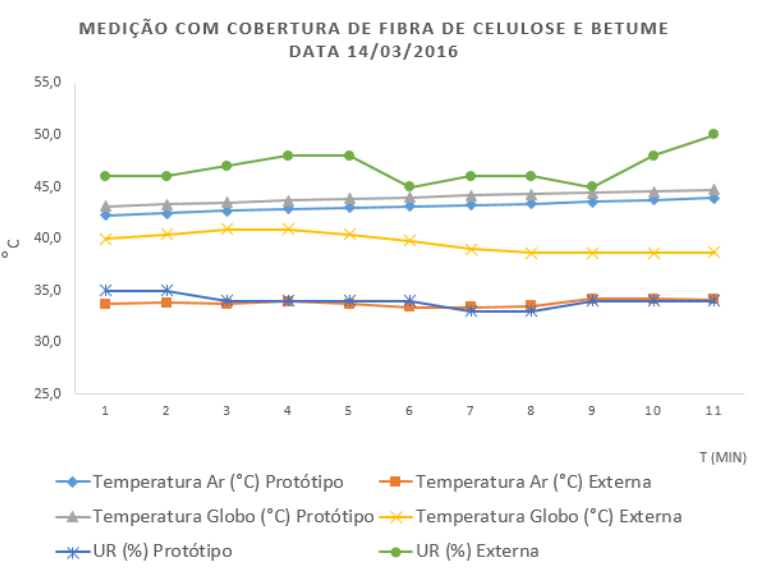

Figura 12. Gráfico da medição com cobertura de fibra de celulose e betume dia 14/03/2016.

Fonte: (Autores, 2016).

\subsubsection{TELHA CERÂMICA}

Por fim, a terceira e última medição foi realizada com a telha cerâmica, no período das $16 \mathrm{~h}$ e $08 \mathrm{~min}$ às $16 \mathrm{~h}$ e $18 \mathrm{~min}$, para tal foi necessária à utilização da estrutura projetada para suporte da telha.

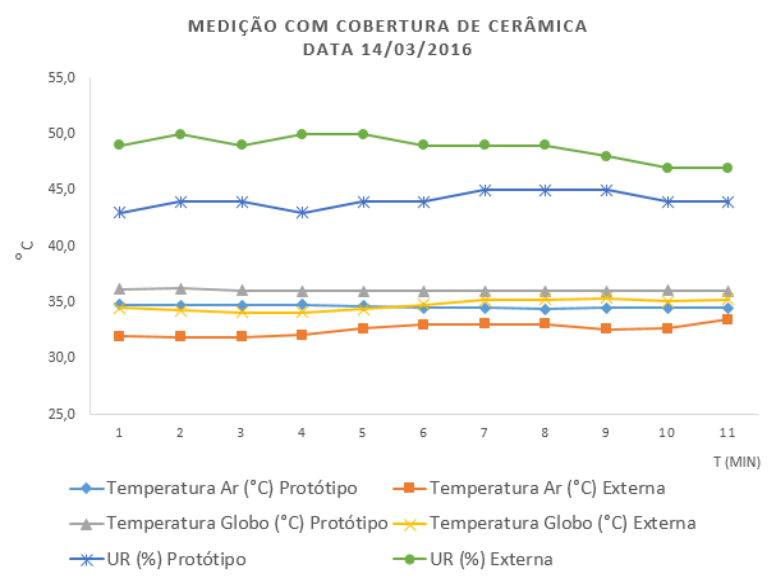

Figura 13. Gráfico da medição com cobertura de cerâmica dia 14/03/2016. Fonte: (Autores, 2016).

\subsection{RESULTADOS DAS MEDIÇÕES DO DIA $17 / 03 / 2016$}

As medições deste dia foram realizadas no período das $11 \mathrm{~h}$ e $20 \mathrm{~min}$ até às $12 \mathrm{~h}$ e $40 \mathrm{~min}$, visando utilizar o período em que os ganhos térmicos são oriundos de planos verticais (cobertura).

As condições climáticas deste dia apresentavam as seguintes características segundo os dados obtidos no site do INPE.

- Direção do Vento: $\mathrm{E}-7 \mathrm{~km} / \mathrm{h}$;

- Umidade Relativa: 38\% em média;

- Temperatura mínima: 21ํㄷ;

- Temperatura máxima: 32ํㄷ.

O céu possuía nenhuma nebulosidade, a sensação térmica era relativamente alta e a velocidade do vento era muito baixa.

\subsubsection{TELHA CERÂMICA}

A medição com a cobertura de cerâmica foi realizada das $11 \mathrm{~h}$ e $21 \mathrm{~min}$ até às $11 \mathrm{~h}$ e $31 \mathrm{~min}$. 


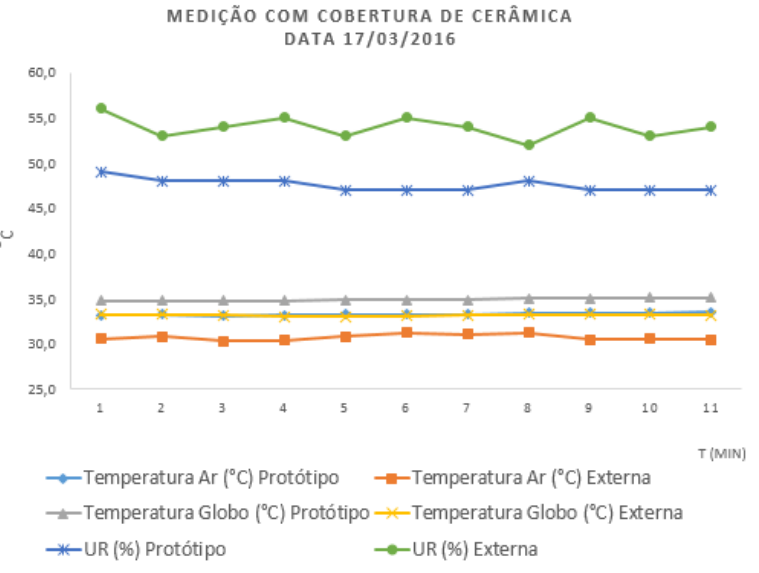

Figura 14. Gráfico da medição com cobertura de cerâmica dia 14/03/2016.

Fonte: (Autores, 2016).

\subsubsection{TELHA DE FIBRA DE CELULOSE E BETUME}

A segunda medição foi realizada com a telha de fibra de celulose e betume, o período foi das $11 \mathrm{~h}$ e $53 \mathrm{~min}$ às $12 \mathrm{~h}$ e $03 \mathrm{~min}$.

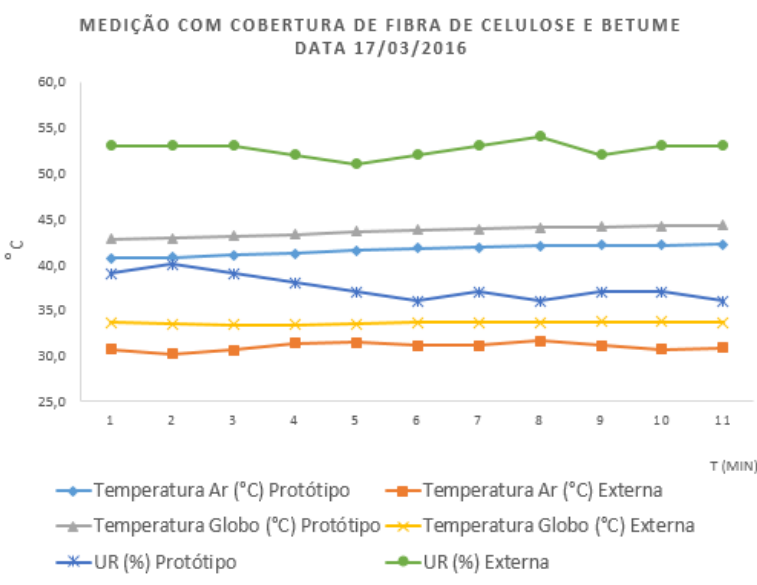

Figura 15. Gráfico da medição com cobertura de fibra de celulose e betume realizada no dia 17/03/2016.

Fonte: (Autores, 2016).

\subsubsection{TELHA DE FIBROCIMENTO}

Por último foram realizadas as medições com as telhas de fibrocimento, começando $12 \mathrm{~h}$ e $26 \mathrm{~min}$ e com término às $12 \mathrm{~h}$ e $36 \mathrm{~min}$.

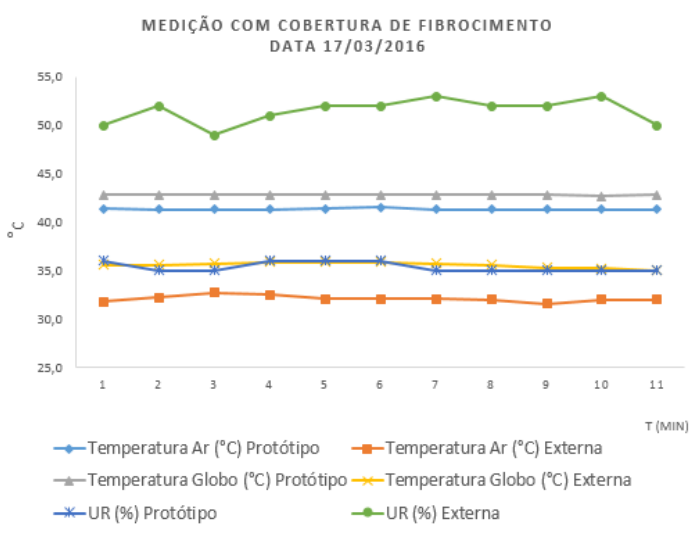

Figura 16. Gráfico da medição com cobertura Fibrocimento dia 17/03/2016. Fonte: (Autores, 2016).

\subsection{RESULTADOS DAS MEDIÇÕES DO DIA 21/03/2016}

As medições deste dia ocorreram no período das $12 \mathrm{~h}$ e $41 \mathrm{~min}$ até as $13 \mathrm{~h}$ e $56 \mathrm{~min}$. No momento das medições fazia muito calor, havia pouca nebulosidade e a velocidade do vento era pequena.

As características climáticas locais segundo a página do INPE, eram:

- Direção do Vento: ND - 7km/h;

- Umidade Relativa: de 30 a 34\%;

- Temperatura mínima: 20ㄷ;

- Temperatura máxima: 35C.

\subsubsection{TELHA CERÂMICA}

As medições com essa cobertura foram realizadas no período das $12 \mathrm{~h}$ e $41 \mathrm{~min}$ até às $12 \mathrm{~h}$ e $51 \mathrm{~min}$ da tarde. A Figura 17 apresenta as variáveis medidas no dia 21/03/2016 da telha cerâmica. 


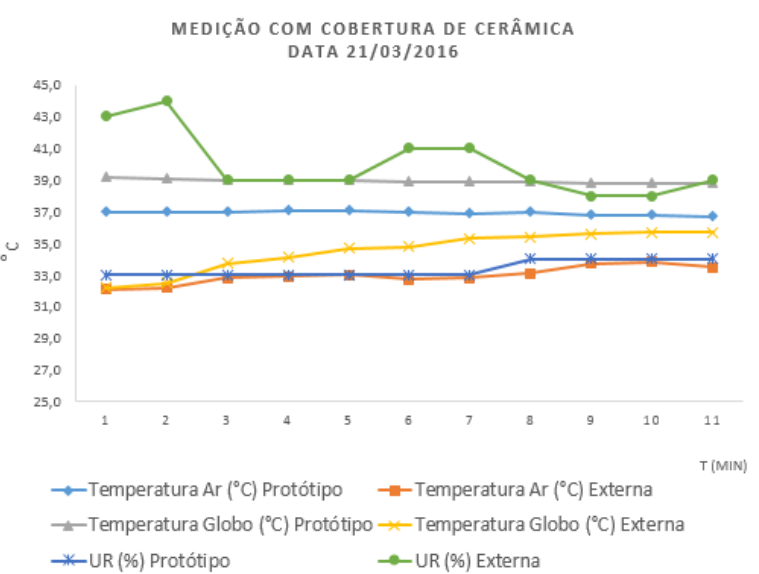

Figura 17. Gráfico da medição com cobertura Cerâmica dia 21/03/2016.

Fonte: (Autores, 2016).

\subsubsection{TELHA DE FIBRA DE CELULOSE E BETUME}

As medições tiveram início as $13 \mathrm{~h}$ e $16 \mathrm{~min}$ e término das $13 \mathrm{~h}$ e $26 \mathrm{~min}$ da tarde, como mostra a Figura 18.

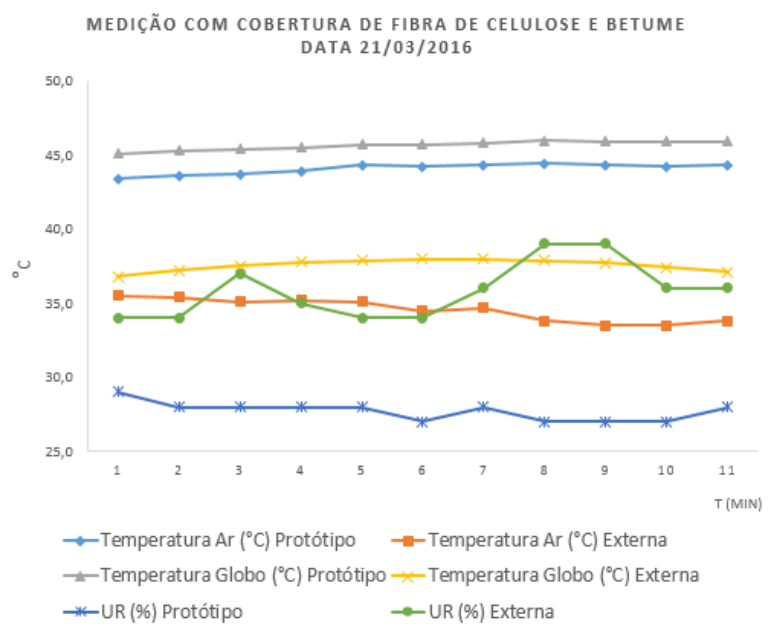

Figura 18. Gráfico da medição com cobertura Fibra de celulose e betume dia 21/03/2016.

Fonte: (Autores, 2016).

\subsubsection{TELHA DE FIBROCIMENTO}

As medições com essa cobertura duraram das $13 \mathrm{~h}$ e $47 \mathrm{~min}$ até às $13 \mathrm{~h}$ e $57 \mathrm{~min}$ da tarde, como apresenta a Figura 19.

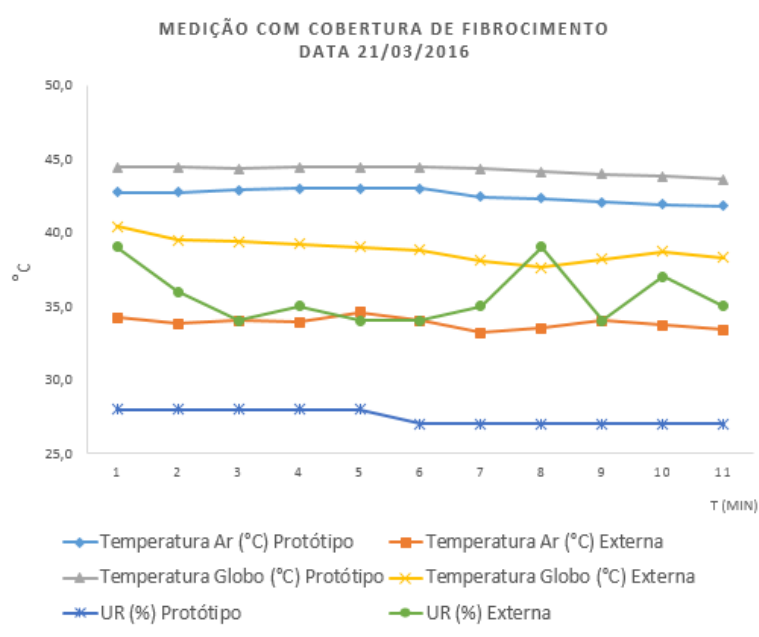

Figura 19. Gráfico da medição com cobertura Fibrocimento dia 21/03/2016. Fonte: (Autores, 2016).

\subsection{RESULTADOS DAS MEDIÇÕES DO DIA 22/03/2016}

Esse consiste no último dia de medições, elas ocorreram no período das $13 \mathrm{~h}$ e $00 \mathrm{~min}$ às $14 \mathrm{~h}$ e $03 \mathrm{~min}$.

O clima do dia estava, assim como nos outros, tipicamente quentes, o céu possuía pouca nebulosidade e quase não havia vento no local. As características apresentadas na página do INPE seguem:

- Direção do Vento: ND - 0 a $7 \mathrm{~km} / \mathrm{h}$;

- Umidade Relativa: de 30 a 50\%;

- Temperatura mínima: $20^{\circ} \mathrm{C}$;

- Temperatura máxima: $33^{\circ} \mathrm{C}$.

\subsubsection{TELHA CERÂMICA}

As medições com essa cobertura tiveram início às $13 \mathrm{~h}$ e término as $13 \mathrm{~h}$ e $10 \mathrm{~min}$. 
MEDIÇÃo COM COBERTURA DE CERÂMICA DATA 22/03/2016

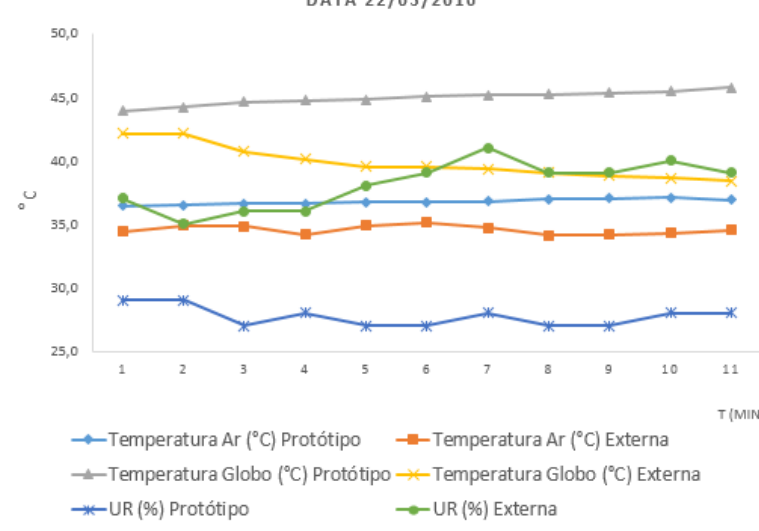

Figura 20. Gráfico da medição com cobertura Cerâmica dia 22/03/2016. Fonte: (Autores, 2016).

\subsubsection{TELHA DE FIBRA DE CELULOSE E BETUME}

As medições com essa cobertura tiveram início às $13 \mathrm{~h}$ e $24 \mathrm{~min}$ e término às $13 \mathrm{~h}$ e $34 \mathrm{~min}$.

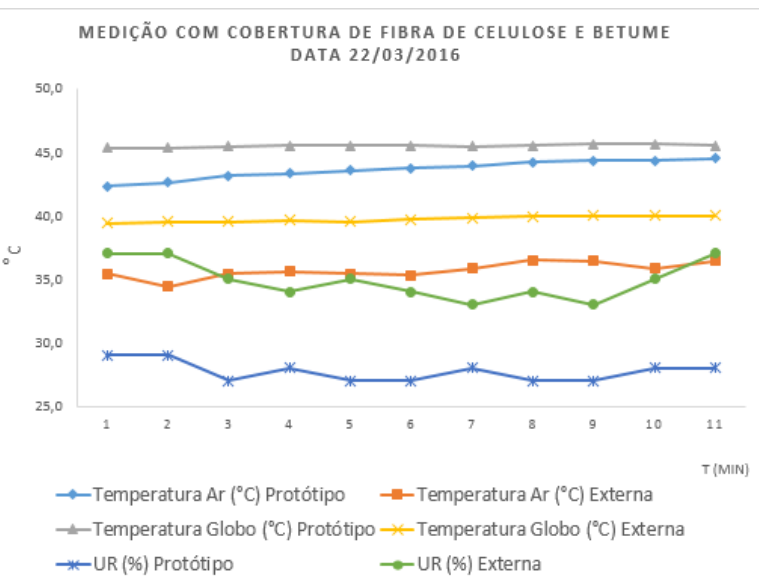

Figura 21. Gráfico da medição com cobertura Fibra de celulose e betume dia 22/03/2016.

Fonte: (Autores, 2016).

\subsubsection{TELHA DE FIBROCIMENTO}

As medições com essa cobertura tiveram início às $13 \mathrm{~h}$ e $53 \mathrm{~min}$ e término às $14 \mathrm{~h}$ e $03 \mathrm{~min}$.
MEDIÇÃO COM COBERTURA DE FIBROCIMENTO DATA 22/03/2016

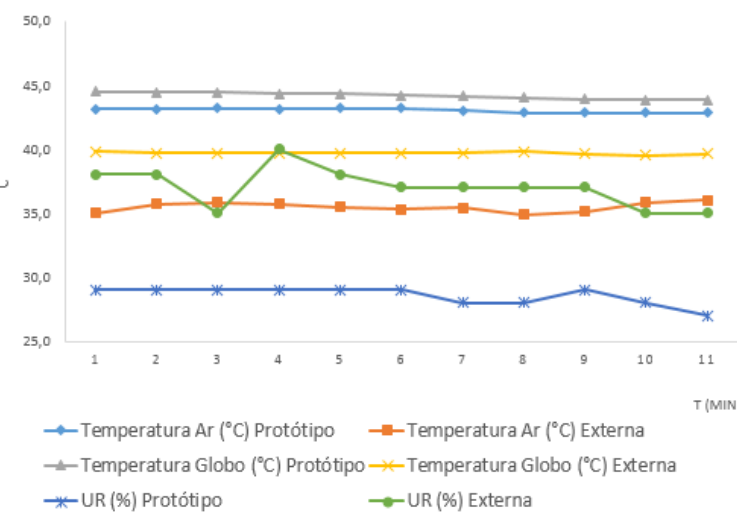

Figura 22. Gráfico da medição com cobertura Fibrocimento dia 22/03/2016. Fonte: (Autores, 2016).

\section{DISCUSSÃO DOS RESULTADOS}

Com os dados obtidos nas medições, foi realizada a comparação das temperaturas máximas e mínimas de cada cobertura, em cada um dos dias, apresentadas nas Figuras 22, 23 e 24, seguidas de suas respectivas discussões.

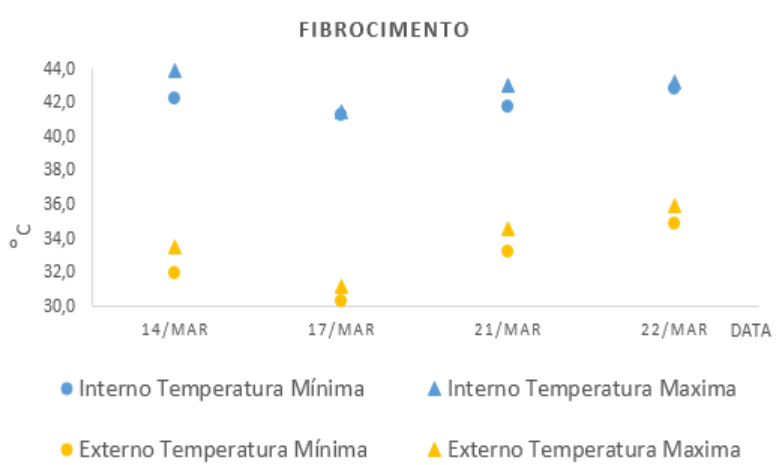

Figura 23. Temperaturas máximas e mínimas externas e internas da cobertura de fibrocimento. Fonte: (Autores, 2016).

A maior temperatura interna registrada foi de $43,9^{\circ} \mathrm{C}$, referente ao dia da medição teste. É importante notar a diferença entre os ambientes externo e 
interno, tendo-se temperaturas menores no exterior, com uma diferença entre a maior temperatura no interior e a menor temperatura externa de $11,9^{\circ} \mathrm{C}$, registrada no mesmo dia em que foi registrada a temperatura máxima, 14 de março de 2016. Esse dado demonstra que há um significativo ganho térmico nesta cobertura.

É importante observar que as maiores amplitudes foram obtidas no dia de medição teste, sendo as mesmas para o ambiente interno e externo respectivamente, $1,7^{\circ} \mathrm{C}$ e $1,5^{\circ} \mathrm{C}$.

Quanto as temperaturas mínimas, a menor temperatura interna registrada foi de $41,3^{\circ} \mathrm{C}$, no dia 17 de março de 2016 . Vale notar que para esta cobertura, as temperaturas internas não foram inferiores a $41^{\circ} \mathrm{C}$.

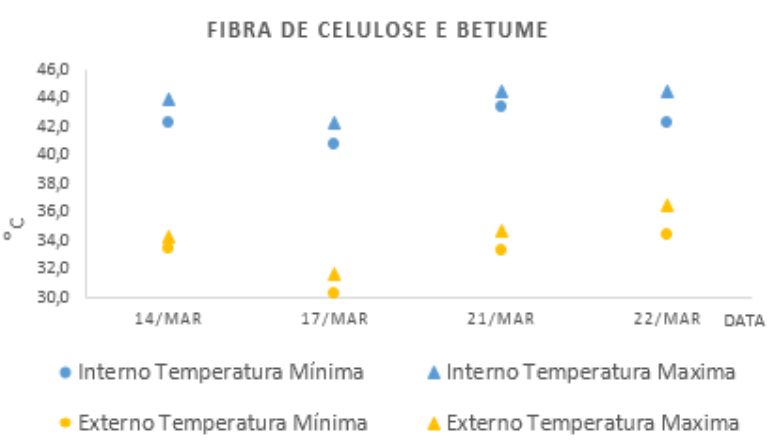

Figura 24. Temperaturas máximas e mínimas externas e internas da cobertura de fibra de celulose e betume. Fonte: (Autores, 2016).

A maior temperatura do ar dentro do protótipo ocorreu no dia 22 de março, com $44,5^{\circ} \mathrm{C}$, enquanto a menor foi no dia 17 , com a temperatura mínima de $40,7^{\circ} \mathrm{C}$. Foi também no dia 22, que as maiores amplitudes térmicas, tanto externas quanto internas, foram verificadas, sendo elas respectivamente, $2,2^{\circ} \mathrm{C}$ e $2,1^{\circ} \mathrm{C}$. Nota-se com esses dados, que as temperaturas internas nesse tipo de cobertura se mantiveram todas acima dos $40^{\circ} \mathrm{C}$. A maior diferença de temperatura máxima interna e mínima externa, ocorreu no dia 17 , sendo o diferencial de $12,0^{\circ} \mathrm{C}$.

Nota-se, portanto, um ganho significativo de calor do ambiente interno em comparação ao externo, para este tipo de cobertura.

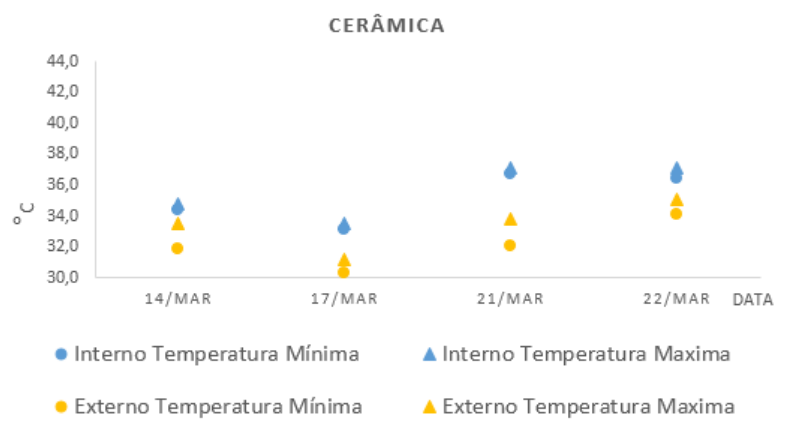

Figura 25. Temperaturas máximas e mínimas externas e internas da cobertura de cerâmica Fonte: (Autores, 2016).

Por fim, para a cobertura de cerâmica, notou-se que a maior temperatura interna registra foi de $37,1^{\circ} \mathrm{C}$, no dia 21 de março de 2016. Por outro lado, temos que a mínima temperatura interna registrada, ocorreu no dia 17 , sendo de $33,1^{\circ} \mathrm{C}$. A maior amplitude interna foi de $0,7^{\circ} \mathrm{C}$, registrada no dia 22 , enquanto a externa foi de $1,7^{\circ} \mathrm{C}$, no dia 21 . 
Neste mesmo dia, a máxima amplitude entre a maior temperatura interna e a menor temperatura externa, foi de $5^{\circ} \mathrm{C}$. Verificou-se que as temperaturas para este tipo de cobertura, ficaram todas abaixo de $40^{\circ} \mathrm{C}$.

A Figura 25 apresenta, em suma, uma comparação dos dados analisados anteriormente, relacionando os extremos, assim como as temperaturas máximas e mínimas das coberturas estudadas, nos dias de medições.

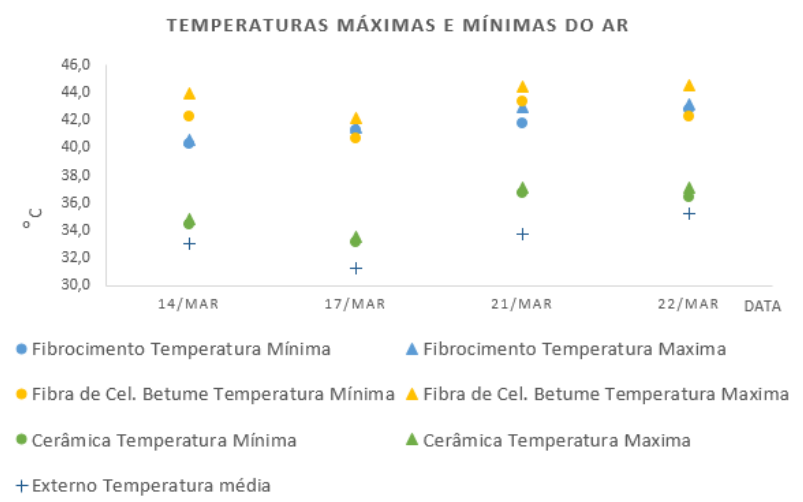

Figura 26. Temperaturas máximas e mínimas do ar.

Fonte: (Autores, 2016).

Comparando as coberturas de fibra de celulose e betume com a de cerâmica, tem-se que a diferença entre as suas máximas temperaturas internas é de $7,4^{\circ} \mathrm{C}$, sendo a da primeira de $37,1^{\circ} \mathrm{C}$, medida no dia 21 de março, e a da segunda, de $44,5^{\circ} \mathrm{C}$, coletada dia 22 de março. A diferença entre as mínimas, foi de $7,6^{\circ} \mathrm{C}$, onde para a de cerâmica registou-se $33,1^{\circ} \mathrm{C}$, contra $40,7^{\circ} \mathrm{C}$ na de fibra de celulose e betume. Analisando uma situação mais crítica, percebe-se que entre a mínima temperatura da telha de cerâmica, $33,1^{\circ} \mathrm{C}$, e a máxima temperatura registrada pela telha de betume, $44,5^{\circ} \mathrm{C}$, temos uma variação de $11,4^{\circ} \mathrm{C}$, valor este bastante elevado, indicando um grande ganho térmico da cobertura de fibra de celulose e betume.

Em seguida, colocou-se em análise as coberturas de fibrocimento e fibra de celulose e betume, devido ao fato das mesmas indicarem temperaturas próximas, sendo as maiores, quando comparadas com a de cerâmica. A maior temperatura para a telha de fibrocimento foi de $43,9^{\circ} \mathrm{C}$, resultante da medição do dia 14 de março. Já a menor, foi de $41,3^{\circ} \mathrm{C}$, medida no dia 17 de março. A variação de temperatura máxima, desses dois tipos de coberturas, foi de $0,6^{\circ} \mathrm{C}$, valor este que se repete para a variação de temperatura mínima. Visando o caso mais crítico, temos que a diferença entre a temperatura máxima da cobertura de fibra de celulose e betume, quando comparado com a temperatura mínima da cobertura de fibrocimento, é de $3,2^{\circ} \mathrm{C}$. Ambas são responsáveis pelas maiores temperaturas, indicando assim os piores resultados, entre as três, quando se trata de conforto térmico.

Finalmente, temos as coberturas de fibrocimento e cerâmica. A diferença de temperatura máxima entre essas duas coberturas, foi de $6,8^{\circ} \mathrm{C}$, e a mínima de $8,2^{\circ} \mathrm{C}$. Analisando a máxima temperatura da 
cobertura de fibrocimento e a menor temperatura da cobertura de cerâmica, temse uma variação de temperatura de $10,8^{\circ} \mathrm{C}$. Apesar da cobertura de fibrocimento não ter apresentado as maiores temperaturas internas, elas são significativamente maiores que a cerâmica.

\section{CONCLUSÃO}

A escolha do tipo de cobertura a se utilizar é uma importante ferramenta para o desenvolvimento de projetos, levando em consideração tanto a eficiência energética da edificação, quanto o conforto térmico do usuário. No presente projeto foram realizadas medições de diferenças de temperatura do ar e de temperatura de globo, variando três tipos de cobertura.

Em todas as medições foi observado o menor ganho térmico da cobertura de cerâmica. Com base nas temperaturas máximas e mínimas dos tipos de coberturas analisadas, observou-se, já na medição teste, que as temperaturas internas do protótipo obtidas com a cobertura de cerâmica eram significativamente menores que as obtidas com outras telhas.

A cobertura de fibra de celulose e betume apresentam as maiores temperaturas, embora a cobertura de fibrocimento não tenha apresentado os maiores valores, seu ganho térmico é significativamente maior que a cerâmica.
Os resultados indicam que apesar de a cobertura de fibra de celulose e betume ser um material reciclado com produção ecologicamente correta, seu uso no que se refere a desempenho térmico deve ser visto com cautela. Os elevados ganhos térmicos oriundos desse material se justificam devido aos materiais compósitos que carregam as características dos materiais originais. A cobertura possui betume em sua composição, material que apresenta baixa condutividade térmica.

Portanto, conclui-se com base nos dados obtidos na presente pesquisa que a partir da comparação dos valores de ganho de calor entre as três coberturas estudadas, que a telha de cerâmica possui o melhor desempenho térmico.

\section{REFERÊNCIAS}

ABNT/CB-02 NBR 13582. CE-02:101.04 Comissão de Estudo de Telha de Barro Cozido. Rio de Janeiro: ABNT, 2001.

ABNT/CB-018 NBR 7581-2. Telha ondulada de fibrocimento parte 2: ensaios. Rio de Janeiro, 2014.

AMORIM, M. C. C. T. A Produção do Clima Urbano em Ambiente Tropical: O Exemplo de Presidente Prudente/SP. Revista Geonorte, São Paulo, v.2, n.5, p.52-64, 2012.

GARTLAND, L. Ilhas de calor: como mitigar zonas de calor em áreas urbanas. 1 ed. São Paulo: Oficina de Textos, 2010. 248p. IBGE. Censo Demográfico. 2010. 
JARDIM, Patrícia R. S. A. Desempenho térmico de coberturas: um estudo comparativo entre as telhas de material reciclado, de fibra e betume, fibrocimento e cerâmica. 2011. 124p. Dissertação (Mestrado) - Universidade Federal do Rio Grande do Norte, Natal, 2011.

SANT'ANNA NETO, J. L.; TOMMASELLI, J. T. G. O tempo e o clima de Presidente Prudente. Presidente Prudente: FCT-UNESP, 2009.

TEIXEIRA, C. F. B. Análise do desempenho térmico de telhas de fibrocimento tratados com revestimentos brancos e submetidas a aspersão de água. 1977. 129p. Tese (Doutorado) - Universidade Estadual de Campinas, Faculdade de Engenharia Civil, Arquitetura e Urbanismo, 1977.

VITTORINO, F.; SATO, N. M. N.; AKUTSU, M. Desempenho térmico de isolantes refletivos e barreiras radiantes aplicados em coberturas. In: ENCAC - COTEDI 2003. Anais... Curitiba, 2003. p. 1277-1284.

WBCSD - WORLD BUSINESS COUNCIL FOR SUSTAINABLE DEVELOPMENT. Energy Efficiency in Buildings: Business realities and opportunities. Facts and Trends, 2011. 